\title{
The Importance of Geospatial Data on Multidrug-Resistant and Extensively Drug-resistant Tuberculosis Distribution in Engela District (Namibia): Retrospective cohort study
}

\author{
Article by Olenga Olenga \\ Dissertation presented for the degree of Master in Public Health at Texila American University \\ E-mail: olengajohn@yahoo.fr
}

\begin{abstract}
Background: Multidrug-resistant tuberculosis (MDR-TB) has become a major public health problem and obstacle to global TB control. MDR-TB is associated with higher case fatality rates, especially among HIV-infected patients, and is much more difficult and costlier to treat than drug susceptible TB. Namibia is the country with the fourth highest TB burden in the world. The incidence rate in 2015 was 651/100 000. Multidrug-resistant tuberculosis (MDR-TB) has become a major public health problem, especially in developing countries, where the MDR-TB burden is the highest. In Namibia, among the regions highly affected by $M D R-T B$, Ohangwena region is facing many challenges. A recent study has demonstrated that the magnitude of the problem by numbers, about 40 per cent of patients admitted to the Katutura State Hospital's TB unit and 30 per cent of patients who commenced treatment at the Engela District Hospital in the Ohangwena Region are Angolan nationals.

Objectives: To determine geospatial Multidrug-resistant and extensively drug-resistant Tuberculosis Distribution in Angola and Namibia; To investigate the impact of geospatial distribution on Multidrugresistant and extensively drug-resistant Tuberculosis. Methods: this is a retrospective cohort study that will be performed on all cases of Multidrug-resistant and extensively drug-resistant Tuberculosis with confirmed laboratory test in Engela District Hospital between January 2013 and December 2017. Geospatial data will be used to illustrate all hypotheses.

Conclusion: this study could be crucial on its genre to establish different gaps between Angolan and Namibian in the management of MDR-TB in Engela district hospital.
\end{abstract}

\section{Problem of statement}

TB has been recognized as a significant public health problem in Namibia since its independence in 1990 and the National TB Control Programme (NTCP) has continually revised its TB control guidelines, in order incorporate updated WHO recommendations and address DR-TB. Few years ago, multidrugresistant tuberculosis (MDR-TB) has become a major public health problem in Namibia. The emergence and controlling the spread of MDR-TB begins with its timely diagnosis (Sagwa 2016). TB can be cured with effective treatment, but with ineffective treatment, MDR TB could develop with grave consequences for the patient, his/her family and community as well as for the health care services. MDR TB develops when TB treatment is ineffective and/or inconsistent. A recent survey conducted in Namibia has shown that drug resistance among TB patients is increasing.

Among Namibian regions affected my MDR-TB, Ohangwena Region is highly concerned. In fact, Ohangwena region is among the region that contributed the most patients with 12\% (MOHSS 2016). A recent report has demonstrating that the magnitude of Angolan nationals admitted in Namibia is high in this region (Lelamobile 2015). In fact, 40 per cent of patients admitted to the Katutura State Hospital's TB unit and 30 per cent of patients who commenced treatment at the Engela District Hospital in the Ohangwena Region are Angolan nationals (Lelamobile 2015).

Our analysis in Engela District Hospital in Ohangwena region has revealed that there is need to improve basic TB control practices to ensure that all TB patients adhere to and complete TB treatment. The community-based DOTS is the main strategy of the TB programme, providing treatment for TB and 
direct observation of intake of medication, dealing with drug-resistant strains of TB and working alongside other programmes to control the spread of TB (MoHSS, 2010)

However, considerable difficulties exist in providing adequate DOT in a vast border between Angola and Namibia but sparsely populated country with high TB prevalence and shortages of trained health care workers.

Nowadays, Using GIS analysis combined with MDR-TB and XDR-TB surveillance can be an effective method for identifying tuberculosis transmission not identified during standard contact tracing methods. The application of these methods can be utilized in countries where contact tracing is routinely performed. These methods can enhance targeted screening and control efforts, with the goal of interruption of disease transmission and ultimately prevalence reduction.

\section{Literature review}

Tuberculosis (TB) is a major public health problem in Namibia, which is ranked 5th highest in the world in terms of the TB incidence rate per 100,000 population ${ }^{3}$ (MOHSS 2016). Multidrug-resistant tuberculosis (MDR-TB) has become a major public health problem and obstacle to global TB control (WHO 2014). MDR-TB is associated with higher case fatality rates, especially among HIV-infected patients (Risk 2012), and is much more difficult and costly to treat than drug susceptible TB (WHO 2010). The worldwide burden of MDR-TB has been growing, and in 2008, there were 440,000 estimated new cases of MDR-TB, or 3.6\% of all incident TB cases, compared to 273,000 estimated new cases (3.2\% of incident TB cases) in 2000 (Zignol 2006; Ricks 2012). However, these estimates may not accurately represent the true global burden of MDR-TB as they are based on surveillance reports from only 114 countries, of which only 10 are sub-Saharan countries with recent or complete national data (WHO 2010).

The incidence rate in 2015 was 651/100 000 (Mavenyengwa 2017). Cases of TB in Namibia are widely distributed throughout the country; however, the majority of cases are reported in the regions of Khomas, Ohangwena, Erongo, and Kavango (Mavenyengwa 2017). Tuberculosis is widely distributed throughout Namibia, with more males infected than females (Mavenyengwa 2017). Males have more resistance to RIF than females (Mavenyengwa 2017). Tuberculosis infection is mainly common in the age group of 20-40 years. A large proportion of MTB patients were also infected with HIV (Mavenyengwa 2017).

Multidrug-resistant tuberculosis (MDR-TB) has become a major public health problem, especially in developing countries, where the MDR-TB burden is the highest (Sagwa 2016). Namibia is facing many challenges about the management of MDR-TB and XDR-TB (Extensively drug resistant TB). In fact, MDR-TB is a form of TB infection caused by bacteria that are resistant to treatment with at least two of the most powerful first-line anti-TB medications (drugs), isoniazid and rifampin. And, XDR-TB is a rare type of MDR TB that is resistant to isoniazid and rifampin, plus any fluoroquinolone and at least one of three injectable second-line drugs (i.e., amikacin, kanamycin, or capreomycin). The emergence of drugresistant strains of TB is a serious threat to controlling the TB infection; drug-resistant, multi-drug resistant and extensively drug-resistant (DR, MDR, and XDR) forms of TB have been reported in Namibia since 2007, and incidence has been drastically increased. (MoHSS, 2010; WHO Namibia, 2009). The number of cases of confirmed MDR-TB has doubled between 2007 and 2009. MDR-TB and XDRTB constitute a serious challenge for controlling the disease because of the higher mortality rate and the financial burden of more costly treatments. (MoHSS, 2010).

Among Namibian regions highly affected by MDR and XDR-TB, Engela District Hospital in the Ohangwena Region is really concerned. A recent study has demonstrating that the magnitude of Angolan nationals admitted in Namibia was high. About 40 per cent of patients admitted to the Katutura State Hospital's TB unit and 30 per cent of patients who commenced treatment at the Engela District Hospital in the Ohangwena Region are Angolan nationals (Lelamobile 2015). This study has shown that there is a need to ensure that the current situation does not significantly derail the commendable progress Namibia has made in TB and Human Immunodeficiency Virus (HIV) control (Lelamobile 2015). Additionally, the 
study explained that untreated persons with TB or HIV, whether from Angola or Namibia, remain the most significant threat to keeping the diseases under control in the country (Lelamobile 2015). In 2012, A total of 11,145 cases of TB were notified among which 4,333 were new smear positive pulmonary cases and 1,410 were previously treated smear positive cases (2). This is important to highlight that 363 cases of drug-resistant TB were diagnosed, including 137 cases multi-drug resistant (MDR) TB and six cases of extensively drug resistant (XDR) TB in Namibia. Only Ohangwena region, 1,078 cases were notified, 533 were diagnosed as new smear positive and 165 cases were previous smear positive patients. Ohangwena region is among the region that contributed the most patients with $12 \%$. Based daily practice, the Engela District in Ohangwena region is the most saturated in TB patients.

In fact, the Engela District Hospital is treating two patients who are both from Angola with Extensively Drug-Resistant TB (XDR-TB), which according to Kamwi is a serious health hazard, because MDR-TB and XDR-TB patients are hospitalized with the other TB patients (New Era 2014). In 2012 and 2013 at least 63 of the 81 patients who defaulted treatment were Angolan nationals, which according to the health minister, negatively impacts the achievement of national and international targets (New Era 2014). "This exerts significant financial and infrastructural pressure on the region and the district, because the hospital does not have infrastructure to isolate these patients (New Era 2014). Although a bilateral agreement between Namibia and Angola has been signed to facilitate the management of communicable diseases between the two countries, the health ministry is still challenged to maintain and ensure that patients are successfully treated, because there are patients who default TB treatment (New Era 2014). Then, the likelihood of developing MDR-TB in those patients is high.

At present, geographic information systems (GISs) are among the most useful tools in epidemiology, as they can be used to identify geographical areas and population groups with a higher risk of sickness or premature mortality and which therefore require higher preventive care or health information and monitoring of diseases in time and space (Moonan 2004). GISs could have many implications in public health policy of TB management. A study conducted in China characterized the geographic and spatiotemporal distribution of confirmed TB (Liu 2012). In this study, we will use geographic information systems will be used to illustrate different gaps in the management of MDR-TB and XDR-TB.

\section{Objectives}

Main objectives:

- To determine geospatial distribution Multidrug-resistant and extensively drug-resistant tuberculosis among patients treated in Engela district Hospital.

- To investigate the impact of geospatial distribution on Multidrug-resistant and extensively drugresistant Tuberculosis.

Specific objectives:

- To estimate the prevalence of MDR-TB and XDR-TB in Engela district from 2013 to 2017.

- To assess the relationship between geospatial data and MDR-TB and XDR-TB outcomes

\section{Methodology}

\section{Study design}

A retrospective cohort study will be performed on data collected on all cases of Multidrug-resistant and extensively drug-resistant Tuberculosis with confirmed laboratory test in Engela District Hospital between January 2013 and December 2017. The study population will be adults (above 18 years old treated for MDR or XDR-TB in this specific period. We will compare Angolans and Namibians who developed MDR or XDR-TB. Angolans will be considered as exposed group and Namibians as no exposed. We hypothesize that geographic areas could impact on tuberculosis treatment. By the way, geographic location is considered as exposure.

We will use a data extraction form with the specific information on geospatial data: patient ID, age, sex, country, region, town, Avenue, Address number, latitude, longitude, phone number, occupation, 
DOI: 10.21522/TIJPH.2013.SE.19.01.Art008

ISSN: 2520-3134

marital status, Income/month, HIV status, Other co-morbidities, date of admission, date of discharge, defaulters, Laboratory results on admission, laboratory results on discharge, MDR, XDR and tuberculosis outcomes.

\section{Study settings}

We will conduct this study in Engela District Hospital which is in the Ohangwena Region. Ohangwena region is populated to 308 951, only Engela district accounts 210 000. Engela District hospital accounts 230 beds, the study will be focused on tuberculosis ward where the admission rate could reach $100 \%$ per month.

\section{Study population}

This study will include all adults' patients (above 18 years old) who were admitted for MDR and XDR tuberculosis in Engela District Hospital in period of January 2013 to December 2017.

\section{Inclusion criteria}

Adults patients (above 17 years old) admitted for pulmonary tuberculosis (PTB) will be considered.

\section{Exclusion criteria}

We will exclude pregnancy women and patients with severe co-morbidities. We will also exclude extra-pulmonary TB without a pulmonary component. In addition, we will exclude all participants whom geospatial data could not be found in the file or by tracing.

\section{Study outcomes}

The primary outcome of the study will be MDR and XDR geospatial mapping distribution between Angola and Namibia. Secondary outcomes will include rates of treatment completion, failure and defaulters.

\section{Sampling technique}

The sample size is calculated by Open Epi software version 5. It is assumed that the odds for having MDR-TB among the previously treated patients compared to the new patients were 2.7. (MOHSS 2016). Using $95 \%$ confidence interval, power of $80 \%$, then Fleiss with CC method is estimated a sample size of 1222 MDR cases.

\begin{tabular}{|c|c|c|c|}
\hline \multicolumn{3}{|c|}{ Sample Size: Retrospective Cohort study } & \\
\hline \multicolumn{3}{|c|}{ Two-sided significance level(1-alpha): } & 95 \\
\hline \multicolumn{3}{|c|}{ Power (1-beta, \% chance of detecting): } & 80 \\
\hline \multicolumn{3}{|c|}{ Ratio of sample size, Unexposed/Exposed: } & 1 \\
\hline \multicolumn{3}{|c|}{ Percent of Unexposed with Outcome: } & 5 \\
\hline \multicolumn{3}{|c|}{ Percent of Exposed with Outcome: } & 13 \\
\hline \multicolumn{3}{|c|}{ Odds Ratio: } & 2.7 \\
\hline \multicolumn{3}{|l|}{ Risk/Prevalence Ratio: } & 2.5 \\
\hline \multicolumn{3}{|l|}{ Risk/Prevalence difference: } & 7.6 \\
\hline & $\begin{array}{l}\text { Kels } \\
\text { ey }\end{array}$ & Fleiss & $\begin{array}{l}\text { Fleiss with } \\
\text { CC }\end{array}$ \\
\hline Sample Size - Exposed & 218 & 217 & 243 \\
\hline Sample Size-Non exposed & 218 & 217 & 243 \\
\hline Total sample size: & 436 & 434 & 486 \\
\hline
\end{tabular}




\section{Data collection and management}

Data will be collected on all consenting TB cases registered at the TB ward in Engela District Hospital between January 2013 and December 2017. All MDR and XDR cases will be included in case that the laboratory investigations have confirmed. Data obtained from medical and laboratory records will comprise demographic data (age, sex, ethnicity, occupation, place of residence), clinical information (type of TB, date of diagnosis, date of registration) and past history of TB. The geographical location of diagnostic and treatment facilities and the residential addresses of all study participants in the study area will be collected using latitude and longitude calculations. In case that the geographical location is not specific, the participants will be excluded from the study. The geo-reference will come from the latitudelongitude projection system obtained from google mapping.

All data will electronically transfer and double entered into an Excel spreadsheet and checked for errors. Geographical analysis will be performed using Geographical Information Systems (GIS) techniques. The geographical co-ordinates will be obtained using the latitude and longitude of each case.

\section{Data analysis}

Statistical analysis will be performed utilizing STATA 14 and GIS statistical software. Namibian and Angolan who were treated for Multidrug-resistant and extensively drug-resistant Tuberculosis will be compared regarding tuberculosis outcomes. Each categorical risk variable will use the relative risk ratio as a measure of association. We will compute the relative risk ratio of MDR, XDR and defaulters between Namibian and Angolans participants. Other factors such as occupation, marital status, Income/month, HIV status, other co-morbidities and TB contact in the family will be incorporated in multiple regression analysis.

The relative risk ratio, Chi squared and p-values will be used to test the hypotheses on differences between Angolan and Namibian. Chi-square testing will be used to compare rates from GIS-region based to those from Angola and Namibia during the same time period. The results will also include the odd ratios $95 \% \mathrm{CI}$.

\section{Ethical considerations}

This investigation will be requested by Namibia's Ministry of Health and Social Services (MOHSS). Investigators will obtain ethical approval from the Engela district Hospital. Then after, clearance will be also obtained from the Region and the Namibian Ethic committee. Texila American University Research Ethics Boards will review the present protocol for obtaining all necessary clearance. The investigation will consist to data abstraction from medical records and laboratory investigations. Data extraction will be conducted in the context of geospacial data and tuberculosis prevalence. A written informed consent will be obtained from each participant while the investigator determines which language the patient felt most comfortable speaking. In case that medical records data and patient tuberculosis data are linked by patient ID, All patients' identifiers will be removed prior to analysis, which will be done anomously. Confidentiality will be maintained throughout the study period (during data collection, data analysis, and reporting of the findings) by assigning the focus group a serial number. No other information of the participants that can identify the person will be recorded during the study.

\section{Data dissemination plan}

The findings of the study will be made available to the TB wards units all over Engela district Hospital. Also, we will publish the study results in any relevant academic journals and present at relevant conferences and academic workshops.

The funds will be obtained from the sponsor and the publisher will be active with the project. Our dissemination organization will be as follows: press releases such as media, booklets and magazine. The report will be shared with other organizations such as government, no governmental organizations, 
DOI: 10.21522/TIJPH.2013.SE.19.01.Art008

ISSN: 2520-3134

students and members of other universities. Posters, brochures, community newsletters will be also used for distribution of information.

\section{Study limitations}

The main limitations in retrospective cohort studies are records that were not designed for the study, the available data may be of poor quality. There is frequently an absence of data on potential confounding factors if the data was recorded in the past. It may be difficult to identify an appropriate exposed cohort and an appropriate comparison group. In addition, differential losses to follow up can also bias retrospective cohort studies. However, we will minimize different bias by tracing the patients in case of missing data.

\section{Conclusion}

As a summary, this study is the first of its genre in Namibia. This study could be crucial on its genre to establish different gaps based on geospatial data between Angolan and Namibian in the management of MDR-TB in Engela district hospital. Furthermore, this study will suggest different public health ways of solving the management of MDR-TB in Engela district hospital.

\section{Budget}

Budget (itemized list of financial requirements to carry out the research successfully, with a substantive motivation for the listed requirements or levels of funding).

calendar for six months

\begin{tabular}{|c|c|c|c|c|c|}
\hline Item & Description & $\begin{array}{l}\text { Unit } \\
\text { cost }\end{array}$ & $\begin{array}{l}\text { No. of } \\
\text { Units }\end{array}$ & $\begin{array}{l}\text { Total } \\
\text { cost }\end{array}$ & $\begin{array}{l}\text { Amount } \\
\text { requested } \\
\text { from the } \\
\text { stakeholders } \\
\end{array}$ \\
\hline \multicolumn{6}{|l|}{ Consumables } \\
\hline $\begin{array}{l}\text { 1. materials and } \\
\text { supplies }\end{array}$ & $\begin{array}{l}\text { Pen, Pencil, plain } \\
\text { papers, toners, Erasers, } \\
\text { flash disk, memory disk }\end{array}$ & & & USD 300 & USD 300 \\
\hline 2. laptop & 1 Laptop & $\begin{array}{l}\text { USD } \\
500\end{array}$ & $\mathrm{X} 1$ & USD 500 & USD 500 \\
\hline 3. STATA 14 Software & $\begin{array}{l}\text { Stata Corporation for } \\
\text { bio-statistical analysis }\end{array}$ & $\begin{array}{l}\text { USD } \\
350\end{array}$ & $\mathrm{X} 1$ & USD 350 & USD 350 \\
\hline $\begin{array}{l}\text { 4. office supplies, } \\
\text { printing \& reproduction }\end{array}$ & record forms & $\begin{array}{l}\text { USD } \\
0.5\end{array}$ & X260 & USD 130 & USD 130 \\
\hline 5. & Miscellaneous & & & USD 100 & USD 100 \\
\hline \multicolumn{6}{|l|}{ Research travel } \\
\hline 1. travel to sites & $\begin{array}{l}\text { Daily travel to for } 1 \\
\text { month }\end{array}$ & USD 5 & X30 & USD 150 & USD 150 \\
\hline $\begin{array}{l}\text { 2. participant /patient } \\
\text { transport }\end{array}$ & 260 participants & USD 3 & X260 & USD 780 & USD 780 \\
\hline \multicolumn{6}{|l|}{ 3. other, specify } \\
\hline Research assistantship & $\begin{array}{l}5 \text { nurses: training for } \\
\text { data collection for } 1 \\
\text { month }\end{array}$ & $\begin{array}{l}\text { USD } \\
400\end{array}$ & $\mathrm{X} 5$ & USD 800 & USD 2000 \\
\hline $\begin{array}{l}\text { Conference } \\
\text { attendance and } \\
\text { publication fees }\end{array}$ & $\begin{array}{l}\text { conferences and } \\
\text { publication in a peer } \\
\text { review journal }\end{array}$ & $\begin{array}{l}\text { USD } \\
1200\end{array}$ & $\mathrm{X} 2$ & $\begin{array}{l}\text { USD } \\
3600\end{array}$ & USD 3600 \\
\hline TOTAL & & & & & USD 7910 \\
\hline
\end{tabular}




\section{Schedule}

\begin{tabular}{|c|c|c|c|c|c|c|c|c|}
\hline \multirow{3}{*}{$\begin{array}{l}\mathbf{S} \\
\mathbf{N}\end{array}$} & \multirow[t]{3}{*}{ Activity } & \multicolumn{7}{|c|}{ Time Period } \\
\hline & & \multirow[t]{2}{*}{2018} & \multicolumn{6}{|c|}{2018} \\
\hline & & & July & August & September & October & November & December \\
\hline 1. & $\begin{array}{l}\text { Finalize the } \\
\text { research } \\
\text { proposal }\end{array}$ & & & & & & & \\
\hline 2. & Secure budget & & & & & & & \\
\hline 3. & $\begin{array}{l}\text { Earn ethical } \\
\text { clearance }\end{array}$ & & & & & & & \\
\hline 4. & $\begin{array}{l}\text { Training of data } \\
\text { collectors }\end{array}$ & & & & & & & \\
\hline 5. & $\begin{array}{l}\text { Pilot study and } \\
\text { revision of the } \\
\text { instrument }\end{array}$ & & & & & & & \\
\hline 6. & Data collection & & & & & & & \\
\hline 7. & $\begin{array}{l}\text { Data entry and } \\
\text { data cleaning }\end{array}$ & & & & & & & \\
\hline 8. & $\begin{array}{l}\text { Data analysis } \\
\text { and produce } \\
\text { draft research } \\
\text { paper } \\
\end{array}$ & & & & & & & \\
\hline 9. & $\begin{array}{l}\text { Share the } \\
\text { research paper } \\
\text { for input }\end{array}$ & & & & & & & \\
\hline 10. & $\begin{array}{l}\text { Incorporate } \\
\text { comments and } \\
\text { finalize the } \\
\text { research project }\end{array}$ & & & & & & & \\
\hline 11. & $\begin{array}{l}\text { Submit the } \\
\text { research paper } \\
\text { for publication } \\
\text { in peer reviewed } \\
\text { journal }\end{array}$ & & & & & & & \\
\hline
\end{tabular}

\section{References}

[1]. Kolifarhood Goodarz, Khorasani-Zavareh Davoud, Salarilak Shaker, Shoghli Alireza, Khosravi Nasim. Spatial and non-spatial determinants of successful tuberculosis treatment outcomes: An implication of Geographical Information Systems in health policy-making in a developing country. 2015;5(3):221-30.

[2]. Lelamobile. Angolans Treated Free of Charge for TB and HIV. In: https://www.lelamobile.com/content/49464/Angolans-Treated-Free-of-Charge-for-TB-and-HIV/. 2015.

[3]. Liu, Y., Li, X., Wang, W., Li, Z., Hou, M., He, Y., Wu, W., Wang, H., Liang, H. and Guo, X., 2012. Investigation of space-time clusters and geospatial hot spots for the occurrence of tuberculosis in Beijing. The International Journal of Tuberculosis and Lung Disease, 16(4), pp.486-491.

[4]. Mavenyengwa RT, Shaduka E, Maposa I. Evaluation of the Xpert(R) MTB/RIF assay and microscopy for the diagnosis of Mycobacterium tuberculosis in Namibia. Infectious diseases of poverty 2017;6(1):13. 
DOI: 10.21522/TIJPH.2013.SE.19.01.Art008

ISSN: 2520-3134

[5]. Migliori Giovanni Battista, Dheda Keertan, Centis Rosella, Mwaba Peter, Bates Matthew, O'Grady Justin, et al. Review of multidrug-resistant and extensively drug-resistant TB: global perspectives with a focus on sub-Saharan Africa. 2010;15(9):1052-66.

[6]. Ministry of Health and Social Services (MOHSS). National Tuberculosis and Leprosy Programme Annual Report: 2015-2016. http://www.mhss.gov.na/files/downloads/ed6_NTLPAnnualReport_20170116_Formatted.pdf 2016.

[7]. Moonan Patrick K, Bayona Manuel, Quitugua Teresa N, Oppong Joseph, Dunbar Denise, Jost Kenneth C, et al. Using GIS technology to identify areas of tuberculosis transmission and incidence. International Journal of Health Geographics 2004;3:23.

[8]. New Era. Angolan TB patients flock to Namibia. In: https://www.newera.com.na/2014/04/07/angolan-tbpatients-flock-namibia/. 2014.

[9]. Patterson Benjamin, Morrow Carl D, Kohls Daniel, Deignan Caroline, Ginsburg Samuel, Wood Robin. Mapping sites of high TB transmission risk: Integrating the shared air and social behaviour of TB cases and adolescents in a South African township. 2017; 583:97-103.

[10]. Ricks Philip M, Mavhunga Farai, Modi Surbhi, Indongo Rosalia, Zezai Abbas, Lambert Lauren A, et al. Characteristics of multidrug-resistant tuberculosis in Namibia. 2012;12(1):385.

[11]. Sagwa EL, Ruswa N, Mavhunga F, Rennie T, Leufkens HG, Mantel-Teeuwisse AK. Comparing amikacin and kanamycin-induced hearing loss in multidrug-resistant tuberculosis treatment under programmatic conditions in a Namibian retrospective cohort. BMC pharmacology \&amp; toxicology 2015;16:36.

[12]. Sagwa EL, Ruswa N, Mavhunga F, Rennie T, Leufkens HG, Mantel-Teeuwisse AK. Adverse events and patients' perceived health-related quality of life at the end of multidrug-resistant tuberculosis treatment in Namibia. Patient preference and adherence 2016; 10:2369-77.

[13]. World Health Organization. Multidrug and extensively drug-resistant TB (M/XDR-TB):2010 Global Report on Surveillance and Response. In: http://apps.who.int/iris/handle/10665/44286. 2010.

[14]. World Health Organization. Guidelines for the programmatic management of drug-resistant tuberculosis. In: http://www.who.int/tb/challenges/mdr/programmatic_guidelines_for_mdrtb/en/. 2014.

[15]. Zignol Matteo, Hosseini Mehran S, Wright Abigail, Weezenbeek Catharina Lambregts-van, Nunn Paul, Watt Catherine J, et al. Global incidence of multidrug-resistant tuberculosis. 2006;194(4):479-85.

[16]. Zvavamwe Simbisayi, Ehlers Valerie J. Implementing a community-based tuberculosis programme in the Omaheke region of Namibia: nurses' perceived challenges. 2008;13(3):54-68. 